\title{
Intracellular Collagen Fibers in the Capsule around Silicone Expanders in Guinea Pigs ${ }^{1}$
}

\author{
Krystyna A. Pasyk, M.D., Ph.D., Eric D. Austad, M.D., \\ AND George W. Cherry, D.PHIL. \\ Section of Plastic Surgery, University of Michigan Medical Center, Ann Arbor, Michigan 48109
}

Submitted for publication March 11, 1983

\begin{abstract}
Ultrastructural studies of fibrous capsules surrounding silicone tissue expanders in guinea pigs revealed a number of fibroblasts containing collagen fibers inside cytoplasm with typical periodicity. These fibers were single or multiple, appeared straight, coiled, or bent, and lay in narrow, undulating membrane spaces. These intracellular collagen fibers were found in as many as $15 \%$ of the cells in capsules between 7 and 12 weeks of expansion. These observations suggest that during capsule development there is some imbalance between the synthesis of collagen fibers and their degradation. It is possible that increased synthesis of collagen fibers as well as their phagocytosis by fibroblasts may exist simultaneously.
\end{abstract}

Remodeling and turnover of connective tissue involves synthesis and degradation of collagen fibers. In the last two decades there has been great interest in the intracellular synthesis of collagen both in vivo $[10,15,28,37$, $46,47]$ and in vitro $[23,24,30,44,50]$, and in the mechanism of collagen degradation and resorption by various connective tissue cells $[6,8,29,39,52,55]$. It is generally supposed that the fibroblasts, in addition to their main role in the synthesis of collagen fibers, also possess the ability to phagocytose these fibers $[48,55,59]$, although no one has yet provided direct proof for phagocytosis of collagen in an in vivo situation [36]. Intracellular collagen fibers have been reported in both normal and pathological conditions.

Self-inflating silicone expanders were implanted in guinea pigs for studies on histology and ultrastructural changes in controlled expanded skin and soft tissues [3, 40]. By electron microscopy we observed in the surrounding fibrous capsules, fibroblasts containing collagen fibers in the cytoplasm. To our

\footnotetext{
' Part of this work was presented at the Plastic Surgery Research Council 27th Annual Meeting, La Jolla, Calif. March 14-17, 1982, and at the Symposium: Soft Tissue Expansion in Reconstructive Surgery, University of Michigan Medical School and the Plastic Surgery Educational Foundation, Ann Arbor, Mich. Nov. 19-20, 1982.
}

knowledge intracellular collagen has not been previously demonstrated in capsules surrounding implants.

The present paper attempts to present the ultrastructural features of intracellular collagen fibers and to discuss this phenomenon.

\section{MATERIALS AND METHODS}

For this study 15 albino Dunklin Hartley guinea pigs, each weighing approximately 400 $\mathrm{g}$, were used. Seven animals were used as controls. Capsules were found in all eight animals which underwent dorsal implantation of Austad-type self-inflating silicone expanders [2]. Expanders were implanted for 7 weeks to 8 months. For light and electron microscopic studies, 32 biopsy specimens were taken under general anesthesia from four different areas of every animal with capsule which formed around the silicone expanders [40]. The specimens were cut into $1-\mathrm{mm}^{3}$ cubes and fixed with $2 \%$ glutaraldehyde solution in cacodylate buffer at $\mathrm{pH} 7.4$ for $4 \mathrm{hr}$ at $4^{\circ} \mathrm{C}$, washed in the same buffer overnight, postfixed with a $1 \% \mathrm{OsO}_{4}$ solution in the buffer for $2 \mathrm{hr}$ and "en bloc" stained with $2 \%$ uranyl acetate for $1 \mathrm{hr}$. Then samples were dehydrated in a series of graded alcohols and propylene oxide and embedded in an epoxy resin. To select areas 
for ultramicrotomy, thick sections were stained with toluidine blue and examined under the light microscope. Ultrathin serial sections were cut with a diamond knife on an LKB Huxley-Ultramicrotome. Ribbons of sections were mounted on copper grids and stained with uranyl acetate and lead citrate. Sections were examined on a Siemens Elmiscop 101 electron microscope operated at 80 $\mathrm{kV}$. Approximately 180 Epon blocks with capsule tissue and 40 blocks with fascia from control animals were examined with the electron microscope. There were no control animals with silicone implants without expansion in this group. This is the subject of a separate project on which we are currently working.

\section{RESULTS}

The thickness of capsules surrounding the silicone expanders was $45-100 \mu \mathrm{m}$, as measured with the light microscope using an intraocular micrometer (American Optical Co.). The capsules were composed of very elongated and flattened fibroblasts, as well as myofibroblasts, which lay between thick bundles of collagen fibers with variable fiber width, oriented parallel to the surface of the implant (Fig.1). In all stages of capsule development, the fibroblasts showed an extensive rough endoplasmic reticulum and prominent cisternae. The cytoplasm of the fibroblasts also had numerous vesicles and vacuoles sometimes filled with osmophilic material. Intracellular collagen fibers with a typical cross-banded periodicity of $640 \AA$ were found in the cytoplasm of the numerous fibroblasts (Fig. 2). This phenomenon was observed in as many as $15 \%$ of the cells in the capsules between 7 and 12 weeks of expansion. The intracellular collagen fibers were single or multiple and lay in narrow, undulating single membrane-bound spaces. These fibers appeared to be mostly straight, although some were coiled or bent. Many of them were cross sectioned (Fig. 3). In some fibroblasts, the fusion of the vesicles with the membrane of the vacuoles containing collagen fibers was seen (Fig. 2c). This may suggest accumulation of the collagen fibers within vacuoles during their synthesis. In other fibroblasts, collagen fibers in close apposition to the plasma membrane were found as well as some located in the membrane-bound profiles, suggestive of phagocytosis (Fig. 4).

\section{DISCUSSION}

Intracellular collagen fibers, similar to those described in the present paper, have been observed in various connective tissue cells in normal and pathological conditions where excessive remodeling and turnover of connective tissue take place. Intracellular collagen has been found in the cytoplasm of fibroblasts during embryogenesis of human fetuses [21, 38], in macrophages during hair growth cycles [39], during cultivation of human skin, in fibroblasts, macrophages, smooth muscle cells and in unidentifiable cells [23]. Intracytoplasmic collagen fibers were present in fibrocytic cells associated with rapid connective tissue remodeling in the periodontium of the mouse, rat, guinea pig, monkey, hamster, and rabbit $[5,6,11,32,52]$, as well as in the periodontal ligament of man [13, 60]. Macrophages, fibroblasts, and smooth muscle cells were involved in the resorption of collagen fibers in the postpartum involuting uterus in animals and humans [7, 26, 33, 51]. Degradation of collagen fibers by intimal smooth muscle cells in atherosclerotic lesions in rabbits [25] and the presence of intracellular collagen in smooth muscle cells of the intimal thickening of human varicose veins have also been reported [27]. Numerous fibroblasts in the junctional zone between old and new connective tissue in animal skin wounds exhibited intracellular collagen $[54,56]$. A similar phenomenon has been reported in fibroblasts associated with fracture repair $[17,18]$. The presence of intracellular collagen in fibroblasts has been found in a few pathological entities: morbus Dupuytren (Dupuytren's contracture) [16], keloids [12], dermatofibrosarcoma protuberans [2], in some fibroblastic tumors [1, $57,58]$ and inflammatory conditions [58], in odontogenic myxoma [20], and carrageenin 




FIG. 1. Three months of tissue expansion. Part of the capsule illustrating fibroblastic cells $(F)$ with dilated endoplasmic reticulum and prominent cisternae and thick bundles of collagen fibers. Note the variable width of the collagen fibers $(\times 17,000)$.

granulomas induced in guinea pigs and rabbits [43]. Intracellular collagen has also been observed in mononuclear phagocytes of fibroblasts in multicentric reticulohistiocytosis [8]. Moreover, sequestered collagen fibers in the cytoplasm of macrophages have been found in epidermolysis bullosa [42], xanthogranuloma [35], and erythema chronicum migrans [49]. Baur et al. [4] have observed the incorporation of collagen fibers within cytoplasmic vacuoles of active fibroblasts and myofibroblasts (which the authors called fibroclasts and myofibroclasts), in hypertrophic scars in humans, and in wound healing tissues in the mouse.

$\Lambda$ ggregation of intracellular collagen fibers within the fibroblasts has been attributed by some authors $[1,16,17,38]$ to increased synthesis of these fibers, and by others $[5,6,8$, $23,27,36,52,53,55,56,60]$ to their phagocytosis during degradation. Presence of collagen fibers inside cytoplasmic vesicles of fibroblasts was interpreted by Gothlin and Ericsson [17] as an aberrant synthesis of these fibers. But the same authors [18], during a radioactive study using thorium dioxide as a 


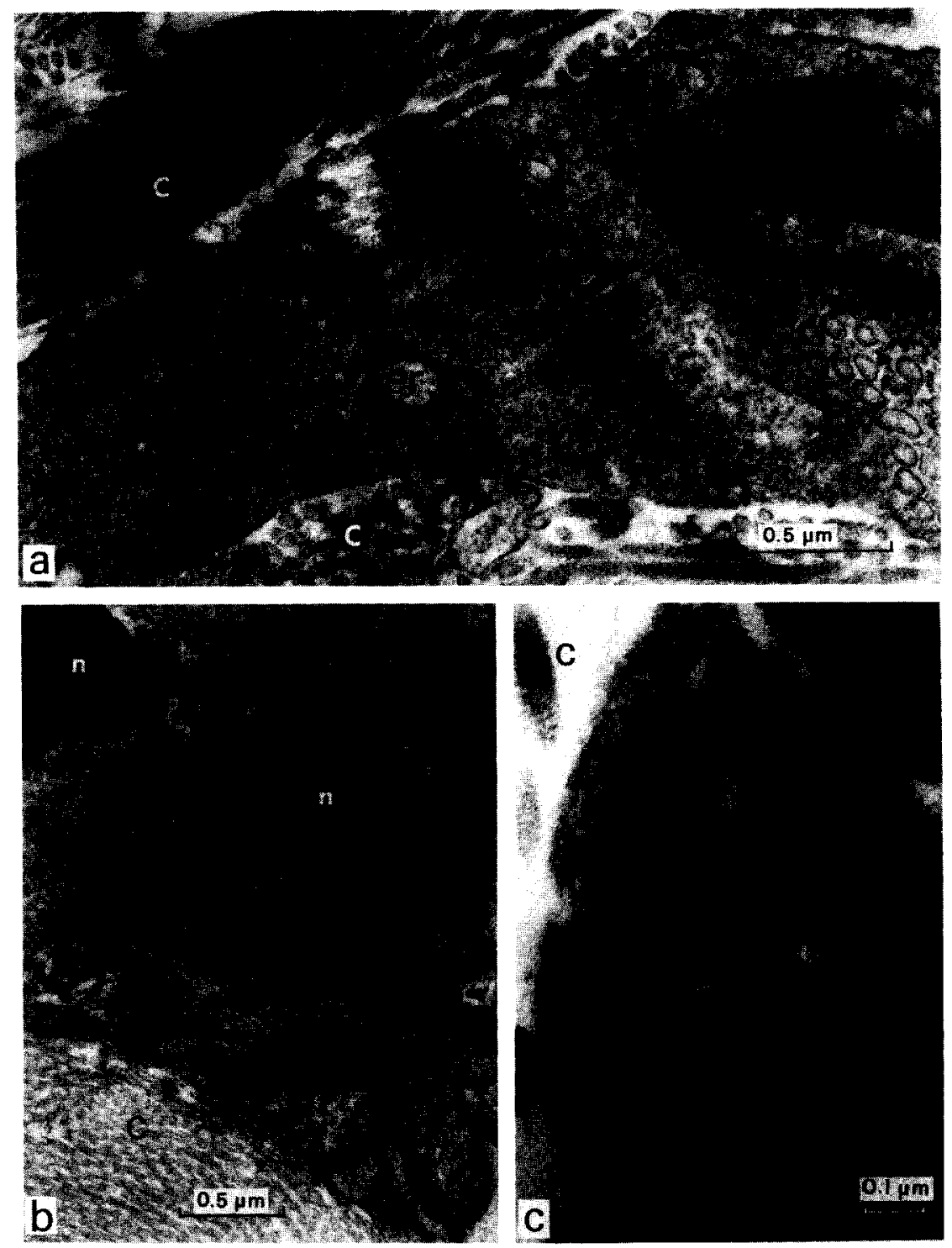

FIG. 2. Three months of tissue expansion. (a) Fragment of collagen fibers (arrows) inside the cytoplasm of fibroblast cut in both longitudinal and transverse section. Nucleus ( $\mathrm{n}$ ), vesicles (v), rough endoplasmic reticulum (er), extracellular collagen fihers $(C)(\times 45,000)$. (b) Fibroblast with intracellularly located bundle of the collagen fibers (arrow). Nucleus $(n)$, mitochondrion $(m)$, extracellular collagen fibers $(C)(\times 26,600)$. (c) Part of the fibroblast with collagen-containing cytoplasmic vacuole and vesicle (arrows). Note the fusion of a vesicle with the unit membrane of the vacuole. Extracellular collagen fibers $(C)(\times 72,000)$.

tracer, proved that collagen fibers had been phagocytosed. In the in vivo situation, the origin of intracellular collagen is uncertain. Melcher and Chan [36] argue an excellent case for the phagocytosis theory. However, even they are careful to state that they interpret the intracellular collagen fibers as having been phagocytosed.

Fibroblasts in normal conditions do not store procollagen in their vesicles. During sta- 


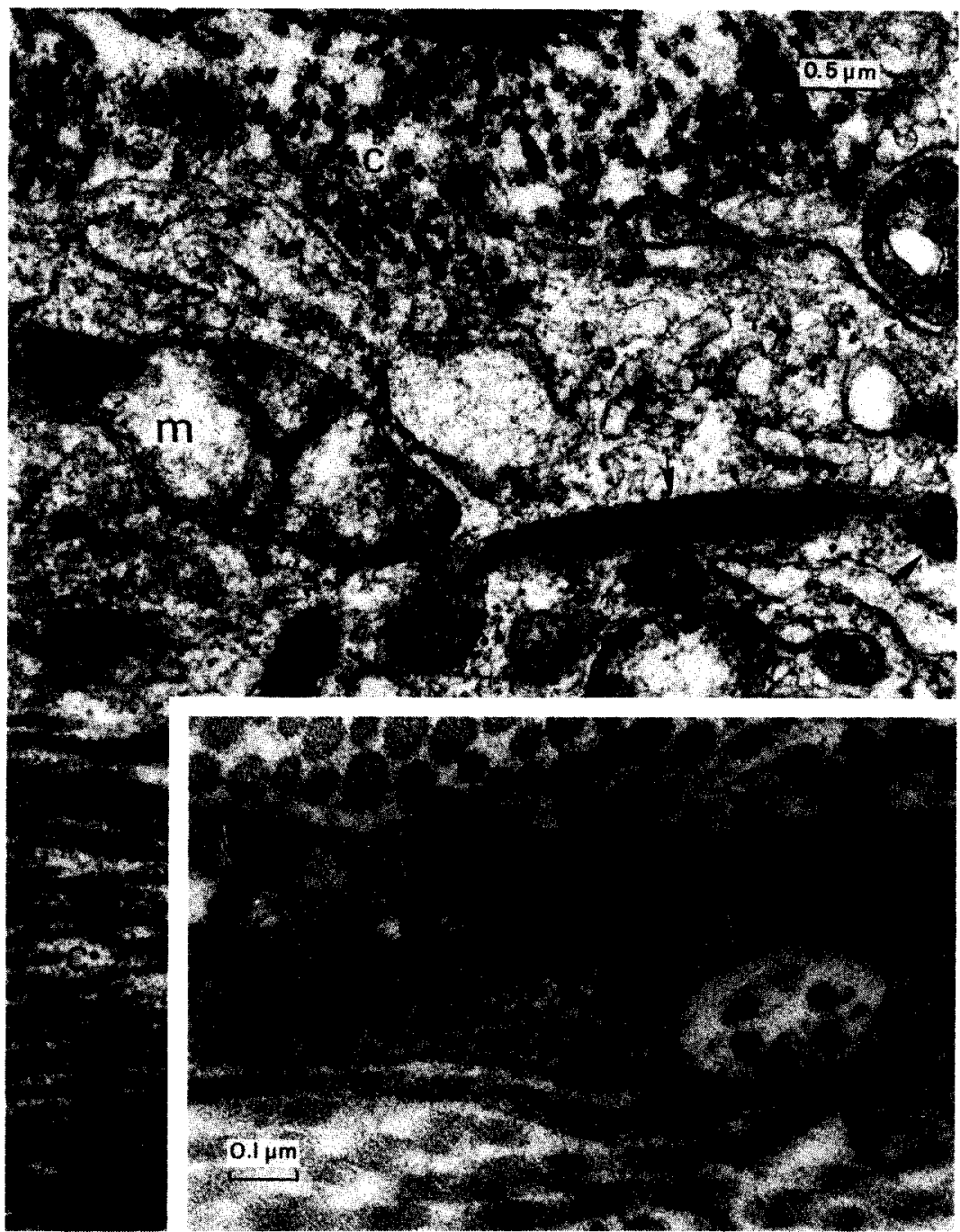

FIG. 3. Two months of tissue expansion. Bundles of collagen fibers with typical periodicity inside the cytoplasm of the fibroblast showing straight, coiled, and bent arrangment. Note fine, undulating membrane surrounding these bundles of fibers (arrows). Mitochondrion $(\mathrm{m})$, extracellular collagen fibers $(\mathrm{C})(\times 35,000)$. Inset: Three months of tissue expansion. Vacuoles with transversally cut collagen fibers inside the cytoplasm of another fibroblast (arrows) $(\times 72,000)$.

ble synthesis, intracellular collagen fibers are not normally found, though they probably exist rarely and are difficult to find [55]. There are two reports about intracytoplasmic collagen in the normal dermis. Hashimoto [21] noted these fibers inside dermal fibroblasts in the normal adult man. Baur et al. [4] found them in the cytoplasm of fibroblasts (fibroclasts) and myofibroblasts (myofibroclasts) in the dermis of normal children ranging in age from 1 to 16 years. These authors stated that fibroclasts and myofibroclasts were observed only rarely in normal dermis (less than $1 \%$ of the cell population). Similarly, very low numbers of fibroblasts containing intracytoplasmic collagen fibers were seen during our ultrastructural study of the foreskin in 2-day-old normal infants [41]. Accumulation of intra- 


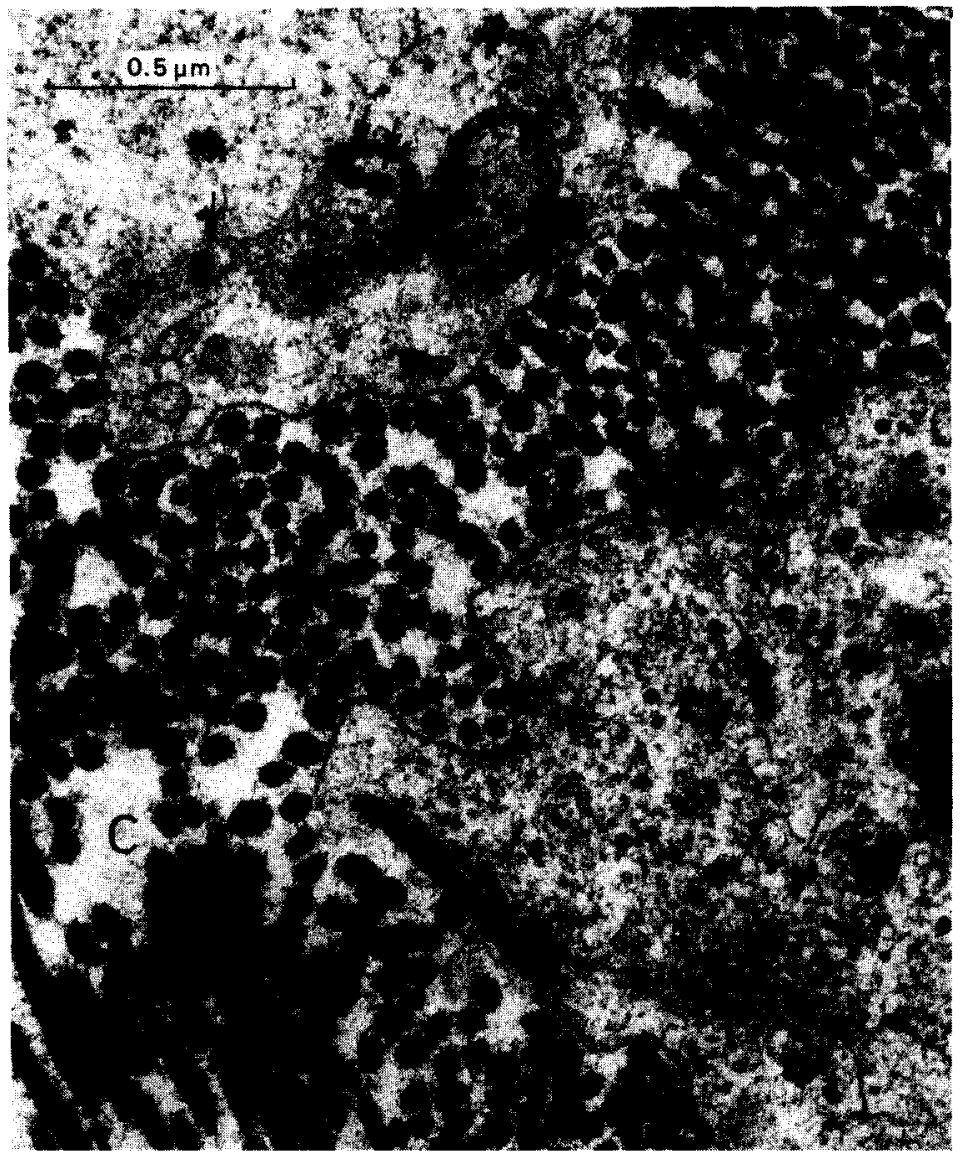

FIG. 4. Seven weeks of tissue expansion. Portion of two fibroblasts showing cross and obliquely cut collagen fibers being phagocytosed (?) (arrows). Extracellular collagen fibers $(C)(\times 52,000)$.

cellular collagen fibers does occur during increased synthesis. Gokel and Hübner [16] described intracellular collagen fibers intermingled with "fibrous long spacing" collagen inside vacuoles of metabolically active fibroblasts in the proliferative phase of morbus Dupuytren (Dupuytren's contracture). These intracellular structures were surrounded by trilaminar membranes of $45 \AA$ (a characteristic of the endoplasmic reticulum) which were continuous with membranes of the endoplasmic reticulum. Similarly Allegra and Broderick [1] reported collagen fibers within tubular sacs of the smooth-surfaced endoplasmic reticulum in a human fibroblastic tumor.
Hentzer [22], however, demonstrated that in dermis various cells can be involved in the degradation of collagen fibers and that lysosomes have an important role in resorption of these fibers. Ten Cate and Deporter [55] stated that, during phagocytosis of collagen fibers, the fibroblasts form a phagosome which fuses with primary lysosomes forming a phagolysosome. The final degenerative process of the collagen fiber takes place within the phagolysosome. Moreover, some authors [11, 22, 53] have been able to demonstrate the activity of the enzyme alkaline phosphatase within phagosome-containing collagen fibers. This is suggestive that collagen fibers are undergoing intracellular digestion. 
On the other hand, it has been known for some time that in most tissues where collagen breakdown occurs, collagen synthesis is also actively taking place $[31,59]$. Biochemical and autoradiographic studies have indicated that remodeling and turnover of connective tissue involves the simultaneous synthesis and degradation of collagen fibers $[9,19,34,45,61]$. Fernandez-Madrid et al. [14], during an ultrastructural study on procollagen section, observed "spindle-shaped" bodies in cytoplasmic vacuoles in chicken embryo fibroblasts. They were recognized as membrane-bound collagen fibers because of their periodicity. These intracellular fibrillar structures were found extremely frequently in the fibroblasts treated with colchicine or vinblastine which block the secretion of procollagen. This phenomenon was interpreted as the first step of autophagocytosis of collagenous products under conditions of inhibited intracellular transport of procollagen. These authors suppose that "these agents, by blocking secretion, magnify a normal process, and that under normal conditions population of procollagen molecules may be processed intracellularly."

Our observation of intracellular collagen fibers in the cytoplasm of fibroblasts in fibrous capsules which are formed around self-inflating silicone expanders is a new finding. We propose that during capsule development there is some imbalance between the synthesis of collagen fibers and their degradation. It is possible that increased synthesis of collagen fibers may occur simultaneously with their increased resorption by fibroblasts. The collagen-rich capsule-containing variable width fibers and great numbers of active fibroblasts displaying vesicles containing collagen fibers may suggest increased synthesis of these fibers. On the other hand, intracytoplasmic collagen fibers within vacuoles and narrow tubules may also suggest the capacity of the fibroblasts to phagocytose and degrade their own product.

\section{REFERENCES}

1. Allegra, S. R., and Broderick, P. A. Desmoid fibroblastoma. Intracytoplasmic collageno-synthesis in a peculiar fibroblastic tumor. Light and ultrastructural study of a case. Iruman Pathol. 4: 419, 1979.

2. Austad, E. D., and Rose, G. L. A self-inflating tissue expander. Plast. Reconstr. Surg. 70: 588, 1982.

3. Austad, E. D., Pasyk, K. A., McClatchey, K. D., and Cherry, G. W. Histomorphological evaluation of guinea pig skin and soft tissue after controlled tissue expansion. Plast. Reconstr. Surg. 70: 704, 1982.

4. Baur, P. S. Jr., Barratt, G. F., Brown, G. M., and Parks, D. H. Ultrastructural evidence for the presence of "fibroclasts" and "myofibroclasts" in wound healing tissues. J. Trauma 19: 744, 1979.

5. Beertsen, W., and Everts, V. The site of remodelling of collagen in the periodontal ligament of the mouse incisor. Anat. Rec. 189: 479, 1977.

6. Beertsen, W., Brekelmans, M., and Everts, V. The site of collagen resorption in the periodontal ligament of the rodent molar. Anat. Rec. 192: 305, 1978.

7. Brandes, D., and Anton, E. Lysosomes in uterine involution: Intracytoplasmic degradation of myofilaments in collagen. J. Gerontol. 24: 55, 1969.

8. Caputo, R., Alessi, E., and Berti, E. Collagen phagocytosis in multicentric reticulohistiocytosis. J. Invest. Dermatol. 76: 342, 1981.

9. Carneiro, J. Synthesis and turnover of collagen in periodontal tissues. In C. P. Leblond and K. Warren (Ed.), The Use of Radioautography in Investigating Protein Synthesis. New York: Academic Press, 1965. P. 247.

10. Chapman, J. A. Morphological and chemical studies of collagen formation 1 . The fine structure of guinea pig granuloma. J. Biophys. Biochem. Cytol. 9: 639, 1961.

11. Deporter, D. A., and Ten Cate, A. R. Fine structural localization of acid alkaline phosphatase in collagencontributing vesicles of fibroblasts. J. Anat. 114: 457, 1973.

12. Dyer, R. F., and Enna, C. D. Ultrastructure of keloid: An unusual incident involving lepromatous leprosy. Int. J. Dermatol. 14: 743, 1975.

13. Eley, B. M., and Harrison, J. D. Intracellular collagen fibrils in the periodontal ligament of man. J. Periodontal Res. 10: 168, 1975.

14. Fernandez-Madrid, F., Noonan, S., and Riddle, J. The 'spindle-shaped' body in fibroblasts: Intracellular collagen fibrils. J. Anat. 132: 157, 1981.

15. Fernando, N. V. P., and Movat, H. Z. Fibrillogenesis in regenerating tendon. Lab. Invest. 12: 214, 1963.

16. Gokel, J. M., and Hübner, G. Intracellular "fibrous long spacing" collagen in Morbus Dupuytren (Dupuytren's contracture). Beitr. Pathol. 161: 176, 1977.

17. Gothlin, G., and Ericsson, J. L. E. Electron microscope studies of cytoplasmic filaments and fibers in different cell types of fracture callus in the rat. Virchows Arch. $B$ 6: 24, 1970.

18. Gothlin, G., and Ericsson, J. L. E. Electron microscopic studies on the uptake and storage of thorium 
dioxide molecules in different cell types of fracture callus. Acta Pathol. Microbiol. Scand. A 81: 523, 1973.

19. Grillo, H. C., and Gross, J. Collagenolytic activity during mammalian wound repair. Dev. Biol. 15: 300, 1967.

20. Harrison, J. D. Odontogenic myxoma: Ultrastructural and histochemical studies. J. Clin. Pathol. 26: 570, 1973.

21. Hashimoto, K. Fibroblast, collagen and elastin. In A. S. Zelickson (Ed.), Ultrastructure of Normal and Abnormal Skin. Philadelphia: Lea \& Febiger, 1967. P. 228.

22. Hentzer, B. Intracellular collagen fibrils in cultured human skin explants. J. Cutan. Pathol. 5: 10, 1978.

23. Hentzer, B., and Kobayasi, T. Intracellular collagen fibrils in cultured human skin. Acta Dermatovenerol. (Stockholm) 59: 477, 1979.

24. Jackson, S. V. and Smiths, R. H. Studies on the biosynthesis of collagen: I. The growth of fowl osteoblasts and the formation of collagen in tissue culture. $J$. Biophys. Biochem. Cytol. 3: 897, 1957.

25. Jurukova, Z. Degradation of collagen fibrils by intimal smooth muscle cells in remodelling cholesterol atherosclerosis in rabbits. Artery 8: 275, 1980.

26. Jurukova, Z., and Milenkov, C. Involvement of smooth muscle cells in collagen degradation in the postpartum uterus. Virchows Arch. B 37: 237, 1981.

27. Jurukova, Z. Smooth muscle cells remodelling collagen in human venous intimal thickening. $J$. $U l-$ trastruct. Pathol., in press.

28. Kajikawa, K., Tanii, T., and Hirono, R. Electron microscopic studies on skin fibroblasts of the mouse with special reference to the fibrillogenesis in connective tissue. Acta Pathol. Japon. 9: 61, 1959.

29. Koob, T. J., and Jeffrey, J. J. Hormonal regulation of collagen degradation in the uterus: Inhibition of collagenase expression by progesterone and cyclic AMP. Biochim. Biophys. Acta. 354: 61, 1974.

30. Kuwabara, H. Collagen formation in tissue culture of fibroblasts from chick embryo hearts. Japan. $J$. Exp. Med. 29: 627, 1959.

31. Lapiere C. M. Mechanism of collagen fibre remodelling. In D. I. Anderson, J. E. Eastoe, A. H. Melcher, and D. C. A. Picton (Eds.), The mechanism of tooth support. Bristol: Wright, 1967. P. 20.

32. I istgarten, M. A. Intracellular collagen fibrils in the periodontal ligament of the mouse, rat, hamster, guinea pig and rabbit. J. Periodontal Res. 8: 335, 1973.

33. Luse, S., and Hutton, R. An electron microscopical study of the fate of collagen in the postpartum rat uterus. Anat. Rec. 148: 308, 1964.

34. Madden, J. W. Rapid metabolic turnover of wound collagen. Surg. Forum. 21: 64, 1970.

35. Malbos, S., Guilhou, J. J., Meynadier, J., Barneon, G., and Baldet, P. Le Xantogranulome de l'adulte. Dermatologica 158: 334, 1979.

36. Melcher, A. H., and Chan, J. Phagocytosis and diges- tion of collagen by gingival fibroblasts in vivo: A study of serial sections. J. Ultrastruct. Res. 77: 1, 1981.

37. Merker, H. J. Elektronenmikroskopische Untersuchungen uber die Fibrillogenese in der Haut menschlicher Embryonen. Z. Zellforsch. 53: 411, 1961.

38. Minguetti, G., and Mair, W. G. P. The developing human muscle: Ultrastructural differences between myoblasts and fibroblasts. Rev. Bras. Pesquisas Med. Biol. 13: 1, 1980.

39. Parakkal, P. F. Involvement of macrophages in collagen resorption. J. Cell Biol. 41: 345, 1969.

40. Pasyk, K. A., Austad, E. D., McClatchey, K. D., and Cherry, G. W. Electron microscopic evaluation of guinea pig skin and soft tissues "expanded" with a self-inflating silicone implant. Plast. Reconstruct. Surg. 70: 37, 1982.

41. Pasyk, K. A. Intracellular collagen fibers in the foreskin of 2-day-old normal infants. Arch. Dermatol., in press.

42. Pearson, R. W. Studies on the pathogenesis of epidermolysis bullosa. J. Invest. Dermatol. 39: 551, 1962.

43. Perez-Tamayo, R. Collagen resorption in carrageenin granulomas. II. Ultrastructure of collagen resorption. Lab. Invest. 22: 142, 1970.

44. Porter, K. R., and Pappas, G. D. Collagen formation by fibroblasts of the chick embryo dermis. J. Biophys. Biochem. Cytol. 5: 153, 1959.

45. Prokop, D. J., and Kivirikko, K. I. Hydroxyproline and the metabolism of collagen. In B. S. Gould (Ed.). Treatise on Collagen, New York: Academic Press, 1968. Vol. 1, Part A, p. 215.

46. Revel, J. P., and Hay, E. L. An autoradiographic and electron microscopic study of collagen synthesis in differentiating cartilage. Z. Zellforsch. 61: 110, 1963.

47. Rohr, H. P., and Jurukova, Z. Beitrag zur Bildung bindegewebiger Matrix in glatten Muskelzellen (Elektronenmikroskopischradioautographische Untersuchungen mit ${ }^{3} \mathrm{H}$-Prolin und ${ }^{35} \mathrm{~S}$-Sulfat am Oestrogen stimulierten Mauseuterus) Pathol. Eur. 3: 571 , 1968.

48. Ross, R., and Benditt, E. P. Wound healing and collagen formation. I. Sequential changes in components of guinea pig skin wounds observed in the electron microscope. J. Biophys. Biochem. Cytol. 11:677, 1961.

49. Sandbank, M., and Feuerman, E. Ultrastructural observation of rickettsia-like bodies in erythema cronicum migrans. J. Cutan. Pathol. 6: 253, 1969.

50. Schwarz, W., Merker, H. J., and Kutzsche, A. Elektronenmikroskopische Untersuchungen uber die Fibrillogenese in Fibroblastenkulturen. Z. Zellforsch. 56: $107,1962$.

51. Tansey, T. R., and Padykula, H. A. Cellular responses to experimental inhibition of collagen degradation in the postpartum rat uterus. Anat. Rec. 191: 287, 1978.

52. Ten Cate, A. R. Morphological studies of fibrocytes in connective tissue undergoing rapid remodelling. $J$. Anat. 112: 401, 1972.

53. Ten Cate, A. R., and Syrbu, S. A relationship between 
alkaline phosphatase activity and the phagocytosis and degradation of collagen by the fibroblast. J. Anat. 117: $351,1974$.

54. Ten Cate, A. R., and Freeman, E. Collagen remodelling in fibroblasts in wound repair. Preliminary observations. Anat. Rec. 179: 543, 1974.

55. Ten Cate, A. R., and Deporter, D. A. The degradative role of the fibroblast in the remodelling and turnover of collagen in soft connective tissue. Anat. Rec. 182: 1,1975 .

56. Uzunian, A. Electron microscopy of collagen resorption by fibroblasts in wound repair of the albino rat skin, Rev. Bras. Pesquisas Med. Biol. 12: 347, 1979.

57. Welsh, R. A. Intracytoplasmic collagen formations in desmoid fibromatosis. Amer. J. Pathol. 49: 515, 1966.

58. Welsh, R. A., and Meyer, A. T. Intracellular collagen fibers in human mesenchymal tumors and inflammatory states. Arch. Pathol. (Chicago). 84: 354, 1967.

59. Woessner, J. F., Fr., Biological mechanism of collagen resorption. In B. D. Gould (Ed.), Treatise on Collagen, New York: Academic Press, 1968. Vol. II, Part B, p. 253.

60. Yajima, T., and Rose, G. G. Phagocytosis of collagen by human gingival fibroblasts in vitro. J. Dent. Res. 56: $1271,1977$.

61. Zika, J. M., Rudolph, R., and Klein, L. Autoradiographic distribution of collagen loss in skin grafts. Anat. Res. 102: 445, 1973. 